\title{
Comparison of advanced offline and in situ techniques of organic aerosol composition measurement during the CalNex campaign
}

\author{
J. Timkovsky ${ }^{1}$, A. W. H. Chan ${ }^{2, a}$, T. Dorst ${ }^{1}$, A. H. Goldstein ${ }^{2,3}$, B. Oyama ${ }^{1,4}$, and R. Holzinger ${ }^{1}$ \\ ${ }^{1}$ Institute for Marine and Atmospheric Research Utrecht, Utrecht University, PO box 80005, 3508 TA, the Netherlands \\ ${ }^{2}$ Department of Environmental Science, Policy, and Management, University of California, Berkeley, California, USA \\ ${ }^{3}$ Department of Civil and Environmental Engineering, University of California, Berkeley, California, USA \\ ${ }^{4}$ Department of Meteorology, Institute of Astronomy, Geophysics, and Atmospheric Sciences, University of São Paulo, Brazil \\ ${ }^{a}$ now at: Department of Chemical Engineering and Applied Chemistry, University of Toronto, Toronto, Ontario, Canada
}

Correspondence to: J. Timkovsky (timkovsky@yahoo.com)

Received: 7 October 2014 - Published in Atmos. Meas. Tech. Discuss.: 12 December 2014

Revised: 27 October 2015 - Accepted: 24 November 2015 - Published: 10 December 2015

\begin{abstract}
Our understanding of formation processes, physical properties, and climate/health effects of organic aerosols is still limited in part due to limited knowledge of organic aerosol composition. We present speciated measurements of organic aerosol composition by two methods: in situ thermaldesorption proton-transfer-reaction mass spectrometry (TDPTR-MS) and offline two-dimensional gas chromatography with a time-of-flight mass spectrometer $(\mathrm{GC} \times \mathrm{GC} / \mathrm{TOF}-$ MS). Using the $\mathrm{GC} \times \mathrm{GC} / \mathrm{TOF}-\mathrm{MS} 153$ compounds were identified, 123 of which were matched with 64 ions observed by the TD-PTR-MS. A reasonable overall correlation of $0.67\left(r^{2}\right)$ was found between the total matched TDPTR-MS signal (sum of 64 ions) and the total matched GC $\times$ GC/TOF-MS signal (sum of 123 compounds) for the Los Angeles area. A reasonable quantitative agreement between the two methods was observed for most individual compounds with concentrations which were detected at levels above $2 \mathrm{ng} \mathrm{m}^{-3}$ using the GC $\times$ GC/TOF-MS. The analysis of monocarboxylic acids standards with TD-PTR-MS showed that alkanoic acids with molecular masses below 290 amu are detected well (recovery fractions above 60\%). However, the concentrations of these acids were consistently higher on quartz filters (quantified offline by $\mathrm{GC} \times \mathrm{GC} / \mathrm{TOF}-$ MS) than those suggested by in situ TD-PTR-MS measurements, which is consistent with the semivolatile nature of the acids and corresponding positive filter sampling artifacts.
\end{abstract}

\section{Introduction}

Aerosol particles are ubiquitous in the atmosphere, and are important for two main reasons. Firstly, they scatter and absorb solar radiation, and change cloud properties affecting climate on Earth (Boucher et al., 2013). Secondly, they penetrate into human lungs, causing increased mortality (e.g. Pope and Dockery, 2006). Atmospheric aerosol has various sources, both natural and anthropogenic (e.g. de Gouw and Jimenez, 2009). Organic aerosol (OA) comprises 20 to $90 \%$ of the total aerosol mass (Kanakidou et al., 2005). OA can be emitted directly (primary OA) but can also be produced in the atmosphere via photochemical oxidation of volatile organic compounds (secondary OA).

Elucidating aerosol chemical composition is key to understanding sources and formation processes and to effectively controlling aerosol amounts in the atmosphere (e.g. Ulbrich et al., 2009). For example, $n$-carboxylic acids are one of the three major classes of organic molecular markers used extensively for OA source apportionment (Sinabut et al., 2005). They are known to be primarily emitted (Legrand and De Angelis, 1996) and produced from secondary photochemical reactions (Kawamura and Sakaguchi, 1999). During the CalNex (California Research at the Nexus of Air Quality and Climate Change) campaign Veres et al. (2011) observed a strong correlation of gas-phase organic acids concentrations with the oxidants $\left(\mathrm{O}_{3}\right.$ and $\left.\mathrm{NO}_{2}\right)$ concentrations. Vogel et al. (2013) reported that the contribution of organic acids to the total submicron OA can be up to $60 \%$. 
Even though many in situ techniques have been deployed to study OA composition (e.g. Jayne et al., 2000; Holzinger et al., 2010a; Weber et al., 2001), it is still commonly characterized on the bulk level using descriptors such as oxygento-carbon $(\mathrm{O} / \mathrm{C})$ ratio, volatility distribution, or total organic carbon mass. Only a limited number of in situ studies have researched $\mathrm{OA}$ at a molecular level using high time resolution (2-hourly or better) measurements (e.g. Williams et al., 2014; Yatavelli et al., 2014; Zhao et al., 2013). Therefore, more detailed studies from various locations and time periods are needed to better understand chemical composition and sources of OA.

Here we deployed two different techniques allowing for detailed chemical composition measurements of OA: (1) in situ thermal-desorption proton-transfer-reaction mass spectrometry (TD-PTR-MS) and (2) offline filter analysis by comprehensive two-dimensional gas chromatography coupled to time-of-flight mass spectrometry $(\mathrm{GC} \times \mathrm{GC} / \mathrm{TOF}-$ MS). The in situ TD-PTR-MS technique was developed at Utrecht University, the Netherlands (Holzinger et al., 2010a, 2013). Organic aerosols are collected and thermally desorbed in situ, and organic compounds are ionized by proton transfer reaction. As a result, one can identify chemical composition of hundreds of compounds constituting the original aerosol and/or fragments of these compounds. Of the total OA, 25-60\% has been directly measured with this technique (Holzinger et al., 2013). GC $\times$ GC/TOF-MS has been applied to organic aerosol analysis to provide additional separation using two-dimensional gas chromatography (e.g. Hamilton et al., 2004; Kallio et al., 2006). Analysis of the samples described in this work has previously been reported with regard to distinguishing the alkane isomers in unresolved complex mixtures (Chan et al., 2013). Here we focus on compounds with a broader range of functional groups that are clearly resolved using GC $\times$ GC/TOF-MS.

In this study we aim to use the GC $\times$ GC/TOF-MS measurements of individual compounds and aerosol mass spectrometer measurements of total organic aerosol to better understand the strengths and weaknesses of the TD-PTR-MS technique for measuring individual chemicals and total organic aerosol respectively. This comparison allows us to provide a broad overview of the aerosol composition using these two complementary techniques. The comparison is performed based on 2 days of measurements during the CalNex 2010 campaign in Pasadena, California.

\section{Experimental methods}

\subsection{Measurement campaign}

The data presented in this paper were obtained during the CalNex field campaign in Pasadena, California, performed from 15 May until 16 June 2010. The site is located approximately $18 \mathrm{~km}$ northeast of downtown of Los Ange- les on the campus of the California Institute of Technology $\left(34.1408^{\circ} \mathrm{N}, 118.1223^{\circ} \mathrm{W}\right)$. More than 40 groups participated in this campaign collecting data characterizing chemical composition, transformation, and quantity of gas and particle constituents of the atmosphere. The in situ TD-PTRMS and aerosol mass spectrometer (AMS) instruments were located in neighbouring air-conditioned containers, and the high-volume $\mathrm{PM}_{2.5}$ filter sampler was located on the roof of one of the buildings on the campus $\sim 200 \mathrm{~m}$ southeast of the containers. The inlet for the TD-PTR-MS instrument was located at the top of a $10 \mathrm{~m}$ scaffolding tower and was equipped with $\mathrm{PM}_{2.5}$ cyclones. The AMS inlet was located $2 \mathrm{~m}$ above the roof of the container housing the instrument and AMS instrument measured submicron aerosols $\left(\mathrm{PM}_{1}\right)$. Filter samples were collected on quartz fiber filters (TissuquartzTM Filters, 2500 QAT-UP, Pall Life Sciences), which were $20 \mathrm{~cm} \times 25 \mathrm{~cm}$, allowing for high-volume $\mathrm{PM}_{2.5}$ sampling at $\sim 1 \mathrm{~m}^{3} \mathrm{~min}^{-1}$.

\subsection{Instrument description}

\subsubsection{The in situ TD-PTR-MS method}

In situ aerosol measurements were carried out with an aerosol sampling unit with two identical inlet systems attached to a proton-transfer-reaction time-of-flight mass spectrometer (PTR-TOF-MS, further referred to as "PTR-MS") (Fig. 1a). The setup has been described in detail elsewhere (Holzinger et al., 2010a, 2013). In short, the air flow passes through $12 \mathrm{~m}$ long copper inlet tubes (ID $=6.5 \mathrm{~mm}$ ), particles are humidified in a humidifier and then they are collected in a collection-thermal-desorption (CTD) cell. Afterwards, the cell is heated up in steps of 50 up to $350{ }^{\circ} \mathrm{C}$ and the emitted species are carried with a flow of nitrogen (ultrapure nitrogen, 5.7 purity, Air Products) into the PTR-MS. The PTRMS was operated with the following settings: drift tube temperature, $120^{\circ} \mathrm{C}$, inlet tube temperature, $180^{\circ} \mathrm{C}$; ion source voltages, $U_{\mathrm{s}}=140 \mathrm{~V}, U_{\mathrm{so}}=92 \mathrm{~V} ; \mathrm{E} / \mathrm{N}, 130 \mathrm{Td}$; extraction voltage at the end of the drift tube, $U_{\mathrm{dx}}=24 \mathrm{~V}$. The intensity of the primary $\mathrm{H}_{3} \mathrm{O}^{+}$ion signal (detected at $m / z$ 21.023, $\mathrm{H}_{3}^{18} \mathrm{O}^{+}$) was typically higher than $5 \times 10^{5}$ counts per second.

After the measurements from the first inlet are finished, the valve system is switched automatically to allow aerosol measurements from the second inlet to start. Subsequent to the measurements from the second inlet, gas-phase measurements (not considered in the current paper) are carried out and then the measurement cycle starts over (see Fig. 1 in Holzinger et al., 2013).

\subsubsection{Filter sampling with offline GC $\times$ GC/TOF-MS analysis}

Filter samples were analysed offline using comprehensive two-dimensional gas chromatography coupled to a time-offlight mass spectrometer $(\mathrm{GC} \times \mathrm{GC} / \mathrm{TOF}-\mathrm{MS}$, hereafter re- 
(a)

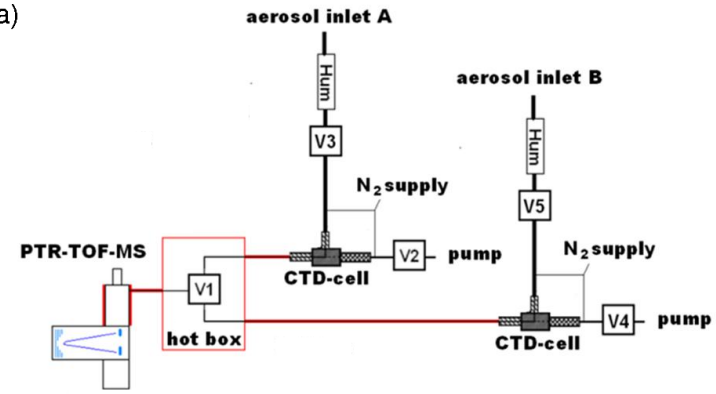

(b)

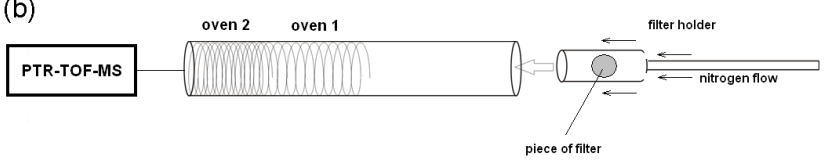

Figure 1. The in situ (a) and offline (b) TD-PTR-MS setups. The following valves are present on scheme A: V1, which allows switching between two aerosol inlets; and V2-V5, which allow switching between sampling and measuring modes for inlet A and B. The figure and the caption are taken from Timkovsky et al. (2015).

ferred to as GC $\times$ GC). Details of the analysis method are described in Chan et al. (2013). In brief, filter punches (total area of $1.6 \mathrm{~cm}^{2}$ ) were thermally desorbed at $320^{\circ} \mathrm{C}$ under helium (TDS3, Gerstel) to a two-dimensional gas chromatograph (Agilent 7890). Comprehensive $\mathrm{GC} \times \mathrm{GC}$ was performed using the Zoex thermal modulator interface, combining a $60 \mathrm{~m} \times 0.25 \mathrm{~mm} \times 0.25 \mu \mathrm{m}$ non-polar capillary column (Rxi-5Sil MS, Restek) for the first-dimension separation (by volatility) with a medium-polarity second-dimension column $(1 \mathrm{~m} \times 0.25 \mathrm{~mm} \times 0.25 \mu \mathrm{m}$, Rtx-200MS, Restek $)$. The second-dimension column was maintained at $15^{\circ} \mathrm{C}$ above the main oven temperature using a secondary oven. Effluent from the second column was analysed using a high-resolution $(\mathrm{m} / \Delta \mathrm{m} \sim 4000)$ time-of-flight mass spectrometer (Tofwerk, Thun, Switzerland) using $70 \mathrm{eV}$ electron impact ionization. Peak detection and compound identification was performed using GC Image software (LLC). Around 1100 peaks were measured at above detection limits. Compounds were identified by confirmation with authentic standards, by mass spectral library search, or, in some cases, based on a unique ion (such as $m / z 85$ for gamma lactones, 217 for steranes) and its location in the two-dimensional chromatogram. Identification of otherwise unresolved branched and cyclic alkanes has also been done on these samples using soft ionization with vacuum ultraviolet radiation (Chan et al., 2013) but these alkanes are not included among the compounds discussed here.

Among the 1100 resolved peaks, the 153 compounds reported here were positively identified with the $\mathrm{GC} \times \mathrm{GC}$ technique, classified by compound groups: aromatic esters, benzofuranones, oxygenated polycyclic aromatic hydrocarbons, phthalates, 2-alkanones, 3-alkanones, alkanoic acids, alkyl esters, delta-lactones, gamma-lactones, nitrogencontaining aromatic compounds ( $\mathrm{N}$-aromatic), polycyclic aromatic hydrocarbons (PAHs), sulfur-containing compounds (S-compounds), amides, hopanes, alkanes, and several compounds were identified at a single $\mathrm{m} / \mathrm{z}$ value (multiple). Another 31 compounds were classified into these compound groups without positive identification. Compound class nicknames are presented in the parentheses and further used in the article to refer to them.

\subsubsection{Aerosol mass spectrometer}

The AMS measurements used in the current study has been described previously in detail (Hayes et al., 2013). In short, AMS allows for measurements of nonrefractory submicron aerosol (organic and inorganic) (DeCarlo et al., 2006). The operational principle of AMS can be presented briefly as follows. Air is sampled through a critical orifice with a consecutive focusing, acceleration, and separation of particles by size. Next, particles are vaporized at $600^{\circ} \mathrm{C}$, ionized by electron ionization $(70 \mathrm{eV})$ and detected with a high-resolution time-of-flight mass spectrometer. Details of AMS operation and data analysis can be found in Hayes et al. (2013).

\subsubsection{Preparation and measurement of standards}

In this paper we present measurements of two types of standards: single compounds and a mixture of compounds. The following single compounds were measured: decanoic, pentadecanoic, and octadecanoic acids. Known quantities of each acid were first dissolved in ethanol, and then an aliquot of the solution containing $10 \mu \mathrm{g}$ of a substance was placed on a quartz filter with a diameter of $5 \mathrm{~mm}$. Next, 2 min were allowed to let most of the solvent evaporate before the filter was inserted in the oven, which is a part of the offline TD-PTR-MS system described in detail by Timkovsky et al. (2015) (Fig. 1b). Each measurement was repeated three times, and two blank filters were measured at the beginning and at the end of each measurement sequence. Blank filters were prepared by adding an aliquot of ethanol without a dissolved standard on a piece of filter.

A mixture containing 77 representative organic compounds and $\mathrm{C} 8-\mathrm{C} 40$ alkanes (this mixture is further called "multicomponent mixture") was carefully prepared by dissolving respective compounds in deuterated acetone. An aliquot of the solution with 0.062 to $20 \mathrm{ng}$ of the substances was placed on quartz filters. In this paper we focus only on acids contained in this standard (21 acids). Again, three filter replicas and two blank filters were measured with the offline TD-PTR-MS. Blank filters were prepared by adding an aliquot of deuterated acetone without a dissolved standard on a piece of filter.

The filter measuring procedure is described in detail by Timkovsky et al. (2015). In short, the sample is placed in the oven and allowed to stabilize for $2 \mathrm{~min}$. Next, the tempera- 
ture of the oven is increased stepwise from 100 to $350^{\circ} \mathrm{C}$ in increments of $50^{\circ} \mathrm{C}$ every $3 \mathrm{~min}$. The desorbed compounds are carried by the $200 \mathrm{~mL} \mathrm{~min}^{-1}$ flow of nitrogen (ultrapure nitrogen, 5.7 purity, Air Products) into the PTR-MS. The operating conditions of the PTR-MS were the same as for the in situ TD-PTR-MS measurements (see Sect. 2.2.1).

\subsection{Data treatment}

\subsubsection{In situ and offline TD-PTR-MS data}

Data evaluation was done with Interactive Data Language (IDL, version 8.1.0, ITT Visual Information Solutions) using custom-made routines described by Holzinger et al. (2010b) and Holzinger (2015). The initial mass lists consisted of 717 and 748 masses for multicomponent mixture and CalNex measurements respectively. Ions associated with primary ions and contaminations from the ion source were removed from the mass lists by filtering out $m / z<40$ amu (except for $m / z 31.017$ and 33.033, corresponding to $\mathrm{CH}_{2} \mathrm{OH}^{+}$ and $\mathrm{CH}_{3} \mathrm{OH}_{2}^{+}$respectively). Inorganic ions (i.e. ions in the $\mathrm{m} / \mathrm{z}$ range $40-50 \mathrm{amu}$ that were matched with an inorganic formula) were also removed from the mass lists. Finally, the mass lists contained 653 and 726 masses for standard and CalNex measurements respectively. The mixing ratios of ions were calculated from the measured intensities by applying the same protonation reaction rate constant for all ions $\left(3 \times 10^{-9} \mathrm{~cm}^{3} \mathrm{~s}^{-1}\right.$ molecule $\left.{ }^{-1}\right)$ (Holzinger et al., 2010b).

For the in situ data analysis, the initial mass spectra were first averaged to obtain data with a time resolution of $5 \mathrm{~s}$. Second, the data were averaged over the measured temperature step ( 3 min each) and the data for all temperature steps were summed. Third, the resulted mixing ratios were converted to mass concentrations for individual ions by multiplying by ion molecular mass, volume of nitrogen used for desorption for one measurement cycle, and dividing by the volume of air sample from which aerosols were collected. Fourth, the data from inlet A and B were merged and averaged to match the filter sampling times. Fifth, the resulted mass concentrations were averaged over the whole comparison period (3031 May) for the data presented in Sect. 3.2.2. The maximum total uncertainty of $\sim 54 \%$ (mostly due to the uncertainty of the reaction rate coefficient) was calculated for these mass concentrations based on the method described by Timkovsky et al. (2015).

The same two initial steps were taken for the analysis of the offline TD-PTR-MS data. The obtained data with a 3 min resolution were processed according to the procedure described in Timkovsky et al. (2015). In short, the instrument background and blank corrected mass at a single temperature step ( $A_{T}$, in ng) was calculated according to Eq. (1):

$$
\begin{aligned}
A_{T} & =\left(\mathrm{VMR}_{i, 0}-\mathrm{VMR}_{i, \text { instrbgd }}-\left(\mathrm{VMR}_{i, \mathrm{fb}}\right.\right. \\
& \left.\left.-\mathrm{VMR}_{i, \text { instrbgd }_{\mathrm{fb}}}\right)\right) \cdot M_{i} \cdot V_{\text {nitrogen }},
\end{aligned}
$$

where $\mathrm{VMR}_{i, 0}$ is the uncorrected mixing ratio of the ion $i$, $\mathrm{VMR}_{i, \mathrm{fb}}$ is the mixing ratio of the ion $i$ observed on the field blank, and $\mathrm{VMR}_{i}$,instrbgd and $\mathrm{VMR}_{i}$,instrbgd_fb are the instrument background mixing ratios of the ion $\bar{i}$ observed during the sample and field blank measurements respectively (all in nmol mol${ }^{-1}$ ). $M_{i}$ is the molecular weight of the ion $i$ (minus $1 \mathrm{amu}$ ) and $V_{\text {nitrogen }}$ is the volume of nitrogen used for desorption at a single temperature step in mol. As a next step, the six masses $A_{T}$ measured for the $50^{\circ} \mathrm{C}$ intervals between 100 and $350{ }^{\circ} \mathrm{C}$ were summed to obtain the total mass of the substance which then compared with the known amount of the substance initially placed on the filters.

\subsubsection{GC x GC quantification}

GC $\times$ GC data were analysed using GC Image (LLC). Peak volumes of quantification ions were used to calculate compound signal and then converted to the total ion signal based on ratios calculated from mass spectra in the NIST08 library. The total ion signals were then converted to on-column mass based on mass calibrations conducted using a representative set of commercially available organic compounds as external standards. For those compounds not commercially available, surrogate standards were assigned based on similarities in molecular structure. Deuterated internal standards were also used to correct for run-to-run variability in instrument response. Mass concentrations were then calculated based on the ratio of filter punch area to total filter area and sampling flow rate.

\subsubsection{Mass matching process}

In order to match ions measured by the TD-PTR-MS with compounds spiked on the filters and those measured with the GC $\times$ GC technique (further referred to as "known compounds") the following procedure was applied. First, we assumed that all known compounds were detected at their protonated mass or, in the case of oxygenated compounds, at the dehydrated fragment (i.e. protonated mass -18.010 , the molecular weight $\left(M_{r}\right)$ of the $\mathrm{H}_{2} \mathrm{O}$ fragment). Other fragmentation patterns are possible but not considered here. We matched the protonated and fragment masses with the ion masses detected by the TD-PTR-MS. A match was assigned if the difference between the protonated or fragment mass of the known compound and an ion detected with the PTRMS was smaller than $250 \mathrm{ppm}$ (corresponding to the mass resolution of the PTR-MS). By applying these rules several measured $\mathrm{m} / \mathrm{z}$ values were consequently attributed to two or more different known compounds. In these cases, both the measured $m / z$ values (protonated mass and fragment mass) and the known compounds were summed up and the sum sig- 
nal was compared. Compounds were considered as not detected when either the detected amount by the TD-PTR-MS was negative after background subtraction or the abovementioned difference was above $250 \mathrm{ppm}$.

For example, 6H-Indolo[3,2,1-de][1,5]naphthyridin6-one $\left(\mathrm{C}_{14} \mathrm{H}_{8} \mathrm{~N}_{2} \mathrm{OH}^{+}, m / z=221.071\right)$ was detected at $m / z \quad 221.089 \mathrm{amu}$ and its fragment was detected at $m / z \quad 203.087$ amu. However, fluoranthene $\left(\mathrm{C}_{16} \mathrm{H}_{10} \mathrm{H}^{+}\right.$, $m / z=203.086)$ and pyrene $\left(\mathrm{C}_{16} \mathrm{H}_{10} \mathrm{H}^{+}, m / z=203.086\right)$ were also detected at $203.087 \mathrm{amu}$. Consequently, 6HIndolo[3,2,1-de][1,5]naphthyridin-6-one, fluoranthene and pyrene were considered as a single compound with $M_{r}$ of $203.087 \mathrm{amu}$, and their measured concentrations were summed in both TD-PTR-MS and the GC $\times$ GC data.

Whenever more than one known compound was measured at the same mass, the most abundant known compound (based on the $\mathrm{GC} \times \mathrm{GC}$ measurements) was chosen to represent all of the measured signal. For example, phenaleno[1,9bc]thiophene and anthraquinone were detected at the same $\mathrm{m} / z$ value (209.059 amu) with the TD-PTR-MS technique. The total averaged mass concentration of phenaleno[1,9bc]thiophene and anthraquinone was 1.57 and $27.70 \mathrm{ng} \mathrm{m}^{-3}$ respectively (based on the $\mathrm{GC} \times \mathrm{GC}$ measurements). Thus, anthraquinone represents $95 \%$ of the signal at that mass, and all of the signal at $209.059 \mathrm{amu}$ was attributed to anthraquinone.

In the case where structural isomers were identified with the $\mathrm{GC} \times \mathrm{GC}$ technique, the corresponding $\mathrm{GC} \times \mathrm{GC}$ concentrations were summed. Mass concentrations of 22 alkanes $\left(\mathrm{C}_{14} \mathrm{H}_{30}-\mathrm{C}_{33} \mathrm{H}_{68}\right)$ measured by the $\mathrm{GC} \times \mathrm{GC}$ were summed and all alkanes were considered as one compound with $M_{r}$ of $113.133 \mathrm{amu}$ as all alkanes are detected with the PTRMS at the same set of masses $(43.055,57.070,71.086 \mathrm{amu}$, and a few other masses). This resulted in the decrease of the GC $\times$ GC data set from 153 to 132 known compounds.

Applying these rules we were able to match 123 of the 132 distinguishable compounds measured with the $\mathrm{GC} \times \mathrm{GC}$ technique to the corresponding 64 ions measured with the TD-PTR-MS technique. The contribution of the unidentified nine compounds is minor $(<2 \%)$ compared to the total mass concentration of the 123 compounds. While we applied rather relaxed rules when attributing detected $\mathrm{m} / z$ values to known compounds, we found that in practice the matches were much closer than $250 \mathrm{ppm}$ : the median difference for 64 ions was $41 \mathrm{ppm}$.

\section{Results}

\subsection{Monocarboxylic acid standards measured by the TD-PTR-MS}

To calibrate the in situ TD-PTR-MS technique for measurements of monocarboxylic acids, a series of filters with known quantities of the acids were prepared and measured with the

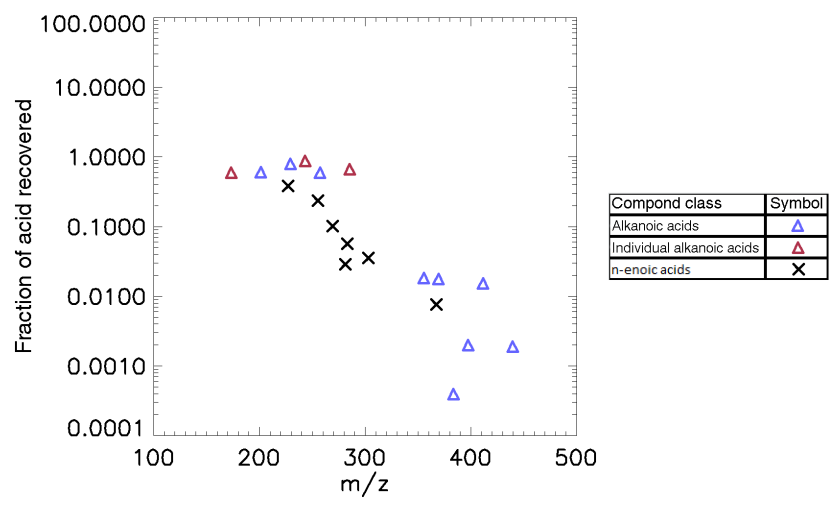

Figure 2. The ratio of the amount of a substance on the filters measured with the offline TD-PTR-MS technique to the known amount of the substance put on the filters (fraction of acid recovered).

offline setup. Figure 2 shows the ratio of the detected amount of substance and the amount of monocarboxylic acids that was applied on the filter, i.e. fraction of acid recovered. The measurements of single compounds (pink triangles in Fig. 2) and the multicomponent mixture (blue triangles and black crosses in Fig. 2) are shown together in this figure. Only the signal of the protonated ion has been used to calculate mass concentrations of alkanoic acids measured with the offline TD-PTR-MS technique. In total, 24 monocarboxylic acids are measured (Fig. 2). The lowest fractions (i.e. lower amounts detected by the TD-PTR-MS) are observed for the high molecular mass acids $\left(M_{r}>300 \mathrm{amu}\right)$. This could be caused by significantly lower than $100 \%$ desorption efficiency off the filters at temperatures up to $350{ }^{\circ} \mathrm{C}$ and thermal decomposition of these high molecular weight substances (e.g. charring) (Yu et al., 2002).

Five out of the 21 monocarboxylic acids $\left(M_{r}>305 \mathrm{amu}\right)$ that were put on the filters in the multicomponent mixture were not detected with the offline TD-PTR-MS technique (in bold in Table 1). This might be caused by the fact that these acids (except for triacontanoic acid) have the highest background signal among the acids with $M_{r}>305 \mathrm{amu}$. Triacontanoic acid is the heaviest acid injected onto the filters and likely indicates the lower volatility limit of the compounds which could be measured with the offline TD-PTR-MS technique. Other heavy monocarboxylic acids $\left(M_{r}>300 \mathrm{amu}\right)$ are strongly underestimated with the offline TD-PTR-MS technique (fraction of acid recovered $\leq 4 \%$ ). Therefore, we can generally conclude that heavy acids $\left(M_{r}>300 \mathrm{amu}\right)$ are not detected well with this technique, which is likely caused by some of the aforementioned reasons.

Alkanoic acids with $M_{r}<290 \mathrm{amu}$ are detected reasonably well (fractions recovered above $60 \%$, Fig. 2). Acids containing one or more double bonds with $M_{r}<290 \mathrm{amu}$ (further referred to as "n-enoic acids") are not detected as well (less than $38 \%$ ), which is possibly caused by their higher affinity to quartz filters and lower resistance to thermal decomposi- 
Table 1. Molecular formula, masses, and fraction recovered of 24 protonated monocarboxylic acids measured as standards on quartz filters individually (in italic) and in the multicomponent mixture. Acids indicated in bold are not detected with the offline TD-PTR-MS technique.

\begin{tabular}{|c|c|c|c|}
\hline Compound & Molecular formula $\cdot \mathrm{H}^{+}$ & Molecular weight & Fraction \\
\hline Decanoic acid & $\mathrm{C}_{10} \mathrm{H}_{21} \mathrm{O}_{2}^{+}$ & 173.154 & $0.59 \pm 0.38$ \\
\hline Lauric acid & $\mathrm{C}_{12} \mathrm{H}_{25} \mathrm{O}_{2}^{+}$ & 201.185 & $0.60 \pm 0.38$ \\
\hline cis-9-Tetradecenoic acid (myristoleic acid) & $\mathrm{C}_{14} \mathrm{H}_{27} \mathrm{O}_{2}^{+}$ & 227.201 & $0.38 \pm 0.24$ \\
\hline Myristic acid & $\mathrm{C}_{14} \mathrm{H}_{29} \mathrm{O}_{2}^{+}$ & 229.217 & $0.80 \pm 0.51$ \\
\hline Pentadecanoic acid & $\mathrm{C}_{15} \mathrm{H}_{31} \mathrm{O}_{2}^{+}$ & 243.232 & $0.87 \pm 0.56$ \\
\hline cis-9-Hexadecenoic acid (palmitoleic acid) & $\mathrm{C}_{16} \mathrm{H}_{31} \mathrm{O}_{2}^{+}$ & 255.232 & $0.23 \pm 0.15$ \\
\hline Palmitic acid & $\mathrm{C}_{16} \mathrm{H}_{33} \mathrm{O}_{2}^{+}$ & 257.248 & $0.60 \pm 0.38$ \\
\hline cis-10-Heptadecenoic acid & $\mathrm{C}_{17} \mathrm{H}_{33} \mathrm{O}_{2}^{+}$ & 269.248 & $0.10 \pm 0.06$ \\
\hline cis,cis-9,12-Octadecadienoic acid (linoleic acid) & $\mathrm{C}_{18} \mathrm{H}_{33} \mathrm{O}_{2}^{+}$ & 281.248 & $0.03 \pm 0.02$ \\
\hline cis-9-Octadecenoic acid (oleic acid; elainic acid) & $\mathrm{C}_{18} \mathrm{H}_{35} \mathrm{O}_{2}^{+}$ & 283.264 & $0.06 \pm 0.04$ \\
\hline Stearic acid & $\mathrm{C}_{18} \mathrm{H}_{37} \mathrm{O}_{2}^{+}$ & 285.279 & $0.66 \pm 0.42$ \\
\hline cis-5,8,11,14,17-Eicosapentaenoic acid (timnodonic acid) & $\mathrm{C}_{20} \mathrm{H}_{31} \mathrm{O}_{2}^{+}$ & 303.232 & $0.04 \pm 0.03$ \\
\hline cis-11-Eicosenoic acid (gondoic acid) & $\mathrm{C}_{20} \mathrm{H}_{39} \mathrm{O}_{2}^{7}$ & 311.295 & - \\
\hline cis-13-Docosenoic acid (erucic acid) & $\mathrm{C}_{22} \mathrm{H}_{43} \mathrm{O}_{2}^{+}$ & 339.326 & - \\
\hline Docosanoic acid (behinic acid) & $\mathrm{C}_{22} \mathrm{H}_{45} \mathrm{O}_{2}^{7}$ & 341.342 & - \\
\hline Tricosanoic acid & $\mathrm{C}_{23} \mathrm{H}_{47} \mathrm{O}_{2}^{7}$ & 355.358 & $0.02 \pm 0.013$ \\
\hline cis-15-Tetracosenoic acid (nervonic acid) & $\mathrm{C}_{24} \mathrm{H}_{47} \mathrm{O}_{2}^{7}$ & 367.358 & $0.01 \pm 0.006$ \\
\hline Tetracosanoic acid (lignoceric acid) & $\mathrm{C}_{24} \mathrm{H}_{49} \mathrm{O}_{2}^{7}$ & 369.373 & $0.02 \pm 0.013$ \\
\hline Pentacosanoic acid & $\mathrm{C}_{25} \mathrm{H}_{51} \mathrm{O}_{2}^{7}$ & 383.389 & $0.0004 \pm 0.0003$ \\
\hline Hexacosanoic acid (cerotic acid; cerotinic acid) & $\mathrm{C}_{26} \mathrm{H}_{53} \mathrm{O}_{2}^{7}$ & 397.405 & $0.002 \pm 0.001$ \\
\hline Heptacosanoic acid & $\mathrm{C}_{27} \mathrm{H}_{55} \mathrm{O}_{2}^{+}$ & 411.420 & $0.02 \pm 0.013$ \\
\hline Octacosanoic acid (montanic acid) & $\mathrm{C}_{28} \mathrm{H}_{57} \mathrm{O}_{2}^{+}$ & 425.436 & - \\
\hline Nonacosanoic acid & $\mathrm{C}_{29} \mathrm{H}_{59} \mathrm{O}_{2}^{+}$ & 439.452 & $0.0019 \pm 0.001$ \\
\hline Triacontanoic acid (melissic acid) & $\mathrm{C}_{30} \mathrm{H}_{61} \mathrm{O}_{2}^{+}$ & 453.467 & - \\
\hline
\end{tabular}

tion. The higher affinity leads to a release at higher temperatures, so that thermal decomposition becomes a competitive desorption pathway and eventually dominates over evaporation.

Based on the presented measurements, a calibration factor for alkanoic acids with $M_{r}<290 \mathrm{amu}$ is developed. Using the averaging of the fractions recovered of six alkanoic acids with $M_{r}<290 \mathrm{amu}$ (three single standards and three from the multicomponent mixture), a calibration factor of 1.45 is found and applied to the alkanoic acid concentrations discussed in Sect. 3.2.2 and 3.2.3. There are three likely explanations for the higher-than-unity calibration factor. First, the same reaction rate coefficient is applied to mixing ratio calculations of all compounds measured by the PTR-MS, and the real reaction rate coefficient for alkanoic acids can be lower than applied (Zhao and Zhang, 2004). Second, a partial thermal decomposition of the acids may occur on filters. Third, lighter alkanoic acids could have (e.g. decanoic) evaporated off of the filter before the filter was placed in the oven for analysis. The first reason is, however, less likely because similar measurements of three alkanoic acids with $M_{r}<290 \mathrm{amu}$ on aluminum foil indicated that the total amount of the acids can be observed with the offline TD-PTR-MS technique for the heavier acids (penta- and octadecanoic acids), while a lower fraction (more loss through evaporation) is observed for the lighter decanoic acid.

\subsection{Comparison of the in situ TD-PTR-MS and offline GC $\times$ GC data}

\subsubsection{Total measured OA signal}

In Fig. 3 we present the time series of total OA mass concentrations measured by the in situ TD-PTR-MS and the AMS instruments (further named "total OA_PTR" and "total OA_AMS" respectively), the total concentration of the 123 compounds measured by the GC $\times \mathrm{GC}$, and the total concentration of the corresponding 64 masses measured by the TDPTR-MS (further named "123 compounds_GC $\times$ GC" and "64 masses_PTR" respectively) over 2 days. The 64 masses constitute $25 \%$ of the total OA mass measured by the TDPTR-MS.

In general, the total OA_PTR and the total OA_AMS correlate well with a correlation coefficient $\left(r^{2}\right)$ of 0.84 . The average percentage of the total OA detected by the TD-PTRMS is $33 \%$. Potential reasons for undetected OA by the TD-PTR-MS, i.e. fragmentation in the PTR-MS and thermal decomposition in the CTD cell, have been discussed in Holzinger et al. (2013). 


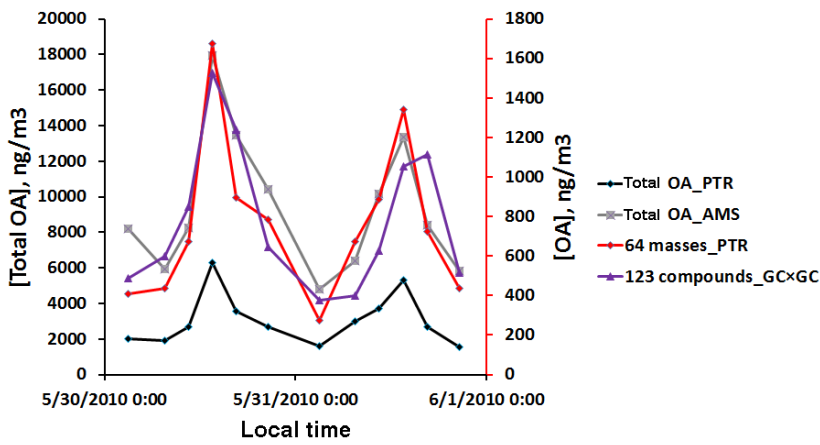

Figure 3. The 2-day cycle of total OA mass concentration (in black, total OA_PTR) and OA mass concentration of 64 masses (in red) measured with the in situ TD-PTR-MS technique, and total OA mass concentration (in grey, total OA_AMS) measured by the AMS and $\mathrm{OA}$ mass concentration of 123 compounds (in violet) measured with the $\mathrm{GC} \times \mathrm{GC}$ technique. Left $y$ axis (in black) corresponds to total OA_PTR and total OA_AMS, and right $y$ axis (in red) corresponds to 64 masses_PTR and 123 compounds_GC $\times$ GC.

A reasonable qualitative and quantitative correlation is observed between the 123 compounds_GC $\times$ GC and the 64 masses_PTR for the Los Angeles area $\left(r^{2}=0.67\right)$. On average, the TD-PTR-MS detected $98 \%$ of the total mass of the "123 compounds_GC $\times$ GC". However, one can notice that the correlation between the 123 compounds_GC $\times$ GC and the 64 masses_PTR is better during the first than the second day of the measurements. This might relate to a different wind direction during the second day and to the fact that the TD-PTR-MS and the HiVol filter sampler were located $\sim 200 \mathrm{~m}$ apart during the campaign. Indeed, the prevailing wind directions were northeast on May 30 and northwest and west on 31 May, based on $48 \mathrm{~h}$ back trajectories using the model HYSPLIT (Draxler and Rolph, 2013; Rolph, 2013).

\subsubsection{Comparison by compound class}

Figure 4 presents mass concentrations of compounds measured with the in situ TD-PTR-MS technique vs. corresponding mass concentrations measured with the $\mathrm{GC} \times \mathrm{GC}$ technique (referred to as "PTR" and "GC $\times$ GC" respectively) averaged over the whole comparison period with $1: 1$ line shown for reference. Compound classes are shown according to the scheme introduced in Sect. 2.2.2.

The PTR/ $(\mathrm{GC} \times \mathrm{GC})$ ratio indicates the ratio of the amount of a substance measured by TD-PTR-MS and by $\mathrm{GC} \times \mathrm{GC}$ respectively. The thin black lines above and below the $1: 1$ line in Fig. 4 mark the $0.25<\mathrm{PTR} /(\mathrm{GC} \times \mathrm{GC})$ $<2.0$ boundaries. Figure 4 indicates that many compounds fall into the range of 0.25 and 2.0, especially for compounds with mass concentrations above $\sim 2 \mathrm{ng} \mathrm{m}^{-3}$ as measured by $\mathrm{GC} \times \mathrm{GC}$. Therefore we conclude that in general, the concentrations of organic species measured with the two techniques agree reasonably well above this threshold.

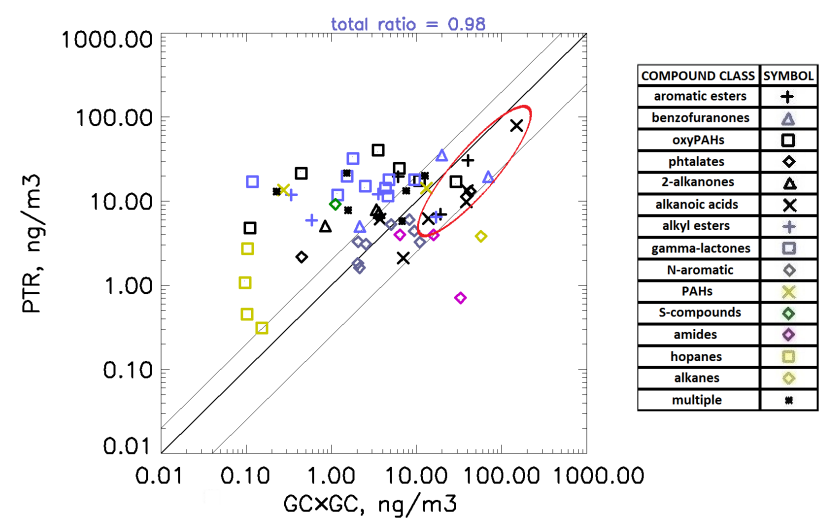

Figure 4. Comparison of aerosol mass concentrations measured with the in situ TD-PTR-MS and GC $\times$ GC technique. The legend shows classes of compounds depicted, which are described in detail in the text. The total PTR/ $(\mathrm{GC} \times \mathrm{GC})$ ratio is 0.98 . The red oval highlights (among other species) four alkanoic acids which are discussed in Sect. 3.2.3. The thin diagonal lines indicate the upper and lower boundaries of the reasonable PTR / $(\mathrm{GC} \times \mathrm{GC})$ ratio $(0.25$ and 2).

An accuracy of $54 \%$ for TD-PTR-MS and $40 \%$ for $\mathrm{GC} \times \mathrm{GC}$ is consistent with boundaries of 0.4 and 3.0 for the PTR/ $(\mathrm{GC} \times \mathrm{GC})$ ratio. The upper boundary (2.0) suggested by Fig. 4 is smaller than the upper boundary (3.0) suggested by the stated accuracy levels (54\% for TD-PTR-MS and $40 \%$ for $\mathrm{GC} \times \mathrm{GC}$ ). This may indicate that the stated accuracy levels are an overestimate of the real instrumental accuracy. The lower boundary (0.25) suggested by Fig. 4 is somewhat lower than the value expected from the stated accuracies (0.4). This may be caused by condensation of semivolatile gas-phase compounds on the large surface of the quartz filters, which is a well-known sampling artifact and constitutes a positive bias of the $\mathrm{GC} \times \mathrm{GC}$ data.

For some compounds (such as hopanes and oxygenated PAHs), GC $\times$ GC detects less than the TD-PTR-MS. In general, for compounds with mass concentrations below $2 \mathrm{ng} \mathrm{m}^{-3}$, the TD-PTR-MS method yielded substantially higher mass concentrations. It should be noted that the 132 compounds measured with the $\mathrm{GC} \times \mathrm{GC}$ technique represent about $10 \%$ of the total OA mass, with another $5-10 \%$ associated with the unresolved complex mixture (Chan et al., 2013). There are likely additional species not quantified with the GC $\times$ GC, that are detected as a sum by PTR-MS at the corresponding $m / z$ values.

At the same time, for alkanes and one amide substantially lower concentrations were detected by TD-PTR-MS (the corresponding points are located at a substantial distance from $1: 1$ line). For alkanes this can be explained by the fact that the main masses at which alkanes are detected (43.055, $57.070,71.086 \mathrm{amu}$ ) were not considered because large contamination from the gas phase did not allow to quantify the 
condensed fraction. More complicated fragmentation in the PTR-MS can likely explain the lower concentrations found for the amide (N,N-dibutylformamide). For all compounds of the class of alkanoic acids (except for decanoic acid), the concentrations were measured to be lower by the TD-PTRMS, which is consistent with a positive sampling artifact that is common to quartz filter collection. The latter will be discussed in the following section.

\subsubsection{Alkanoic acids}

The four alkanoic acids shown in Fig. 4 as black crosses in a red oval are n-dodecanoic, n-tridecanoic, n-tetradecanoic, and $\mathrm{n}$-hexadecanoic acids. These four compounds are among the most abundant species measured by the GC $\times$ GC (three among the seven compounds with the highest concentrations, see Fig. 4). To calculate the mass concentrations of the alkanoic acids measured with the in situ TD-PTR-MS technique, only the intensity of the parent ion signal was considered and multiplied by the calibration factor (1.45) developed for alkanoic acids (see Sect. 3.1). Even after applying this correction factor, the PTR / $(\mathrm{GC} \times \mathrm{GC})$ ratios for the acids are below unity (Table 2). The semivolatile nature of the acids is a possible reason for this disagreement. If vapours of these acids condensed on the quartz filter during sampling an overestimation of the mass concentrations obtained with the GC $\times$ GC technique could be explained. This hypothesis is supported by the fact that positive artifacts have been shown to be more severe on filters with short air sampling duration. For example, Timkovsky et al. (2015) demonstrated substantial positive filter sampling artifacts on filters sampled for $24 \mathrm{~h}$, which were much reduced with sampling durations of 48 and $72 \mathrm{~h}$.

The fraction of the amount of a compound in the particle phase $\left(F_{\mathrm{p}, i}\right.$, amount in the particle phase divided by the total amount in the particle and the gas phase) can be calculated according to the procedure described by e.g. Yatavelli et al. (2014). Compounds for which $F_{\mathrm{p}, i}$ is significantly lower than unity are considered to be semivolatile. $F_{\mathrm{p}, i}$ is calculated based on the activity coefficient, vapour pressure, ambient temperature, and total OA mass concentration. We used the average activity coefficient calculated for alkanoic acids (1.6) based on Chandramouli et al. (2003). If a component has an activity coefficient above unity within a mixture, the component has a weaker interaction with other molecules in the condensed phase than with itself, and its effective vapour pressure is higher than the pure component vapour pressure. Vapour pressures for do-, tetra-, and hexadecanoic acids (Table 2) have been measured by Cappa et al., 2008. Assuming that the logarithm of the vapour pressure of an alkanoic acid has a linear dependency on the number of carbon atoms in the molecule (Goldstein and Galbally, 2007), we calculate the vapour pressure for tridecanoic acid to be $3.2 \times 10^{-6} \mathrm{hPa}$ using known vapour pressures of do-, tetra-, and hexadecanoic acids (Table 2). Using an ambient temperature of $25^{\circ} \mathrm{C}$ and total OA of $9.4 \mu \mathrm{g} \mathrm{m}^{-3}$ (measured by the AMS), $F_{\mathrm{p}, i}$ was found to be substantially lower than unity for three out of the four acids (do-, tri-, and tetradecanoic acids, Table 2). This confirms their semivolatile nature and their potential to cause positive filter sampling artifacts when gas-phase molecules condense on the large surface of the quartz filters. This is also consistent with Sihabut et al. (2005) who observed a high contribution from gas-phase to particle-phase measurements on filters of alkanoic acids containing between 10 and 14 carbon atoms.

Since $F_{\mathrm{p}, i}$ for hexadecanoic acid is unity, it is expected to be fully in the particle phase and is not prone to positive filter sampling artifacts (Table 2). This is again consistent with Sihabut et al. (2005), who showed that only a little contribution to particle-phase measurements is observed from gas phase with filter sampling of alkanoic acids containing between 15 and 18 carbon atoms. The PTR/ $(\mathrm{GC} \times \mathrm{GC})$ ratio $(0.53)$ for hexadecanoic acid is within the expected range (0.4-3.0) given by the combined accuracies of TD-PTR-MS and GC $\times$ GC. However, further study is needed to exclude the possibility that this low ratio may have resulted from a negative sampling artifact for the in situ TD-PTR-MS.

The full 2-day time series for the four alkanoic acids obtained with the TD-PTR-MS and the GC $\times$ GC method are presented in Fig. 5. The clear diurnal cycle detected by the TD-PTR-MS for all four acids is consistent with the diurnal variation of semivolatile compounds observed by the TDPTR-MS (Holzinger et al., 2013) and the AMS (Hayes et al., 2013) during the same field campaign. The highest correlation coefficient $(r, 0.69)$ between the TD-PTR-MS and $\mathrm{GC} \times \mathrm{GC}$ measurements is observed for hexadecanoic acid among the four acids (Table 2), which is the most abundant and least volatile compound within this compound group. It is mainly present in the particle phase and thus is not subject to a positive filter sampling artifact (Fig. 5d). Poor correlation is observed for tri- and tetradecanoic acid (Fig. 5b and $\mathrm{c}$ respectively) which may be caused by the semivolatile nature of the acids and potential measurement artifacts by the $\mathrm{GC} \times \mathrm{GC}$ technique. The latter may be due to the fact that the acids were not derivatized prior to $\mathrm{GC} \times \mathrm{GC}$ analysis. For dodecanoic acid a reasonable qualitative correlation is observed. However, quantitative agreement is poorer than for the other measured acids, which is likely caused by the relatively high volatility of the acid. As shown in Timkovsky et al. (2015), the larger concentrations measured by GC $\times \mathrm{GC}$ may be caused by condensation of the gas-phase fraction of the acids during filter sampling. The poor correlation for triand tetradecanoic acid is currently not understood.

\section{Conclusions}

A comparison of the in situ TD-PTR-MS and offline quartz filter analysis by the GC $\times$ GC/TOF-MS technique, the calibration measurements with the offline TD-PTR-MS tech- 
Table 2. Calculated partitioning coefficients $F_{\mathrm{p}, i}$, observed PTR/ $(\mathrm{GC} \times \mathrm{GC})$ ratios averaged over the considered period, vapour pressures of dodecanoic, tridecanoic, tetradecanoic and hexadecanoic acids, and correlation coefficients $(r)$ of the TD-PTR-MS and the GC $\times$ GC measurements of the acids.

\begin{tabular}{lrrrr}
\hline Compound & $F_{\mathrm{p}, i}$ & $\begin{array}{r}\mathrm{PTR} /(\mathrm{GC} \times \\
\mathrm{GC}) \text { ratio }\end{array}$ & $\begin{array}{r}\text { Vapour pressure, } \\
\mathrm{hPa}\end{array}$ & $\begin{array}{r}r, 2 \mathrm{GC} \\
\mathrm{vs} . \mathrm{PTR}\end{array}$ \\
\hline Dodecanoic acid & 0.03 & 0.25 & $2.3 \times 10^{-5}$ & 0.65 \\
Tridecanoic acid & 0.17 & 0.45 & $3.2 \times 10^{-6}$ & -0.68 \\
Tetradecanoic acid & 0.48 & 0.31 & $7.0 \times 10^{-7}$ & 0.46 \\
Hexadecanoic acid & 1.00 & 0.53 & $1.3 \times 10^{-9}$ & 0.69 \\
\hline
\end{tabular}
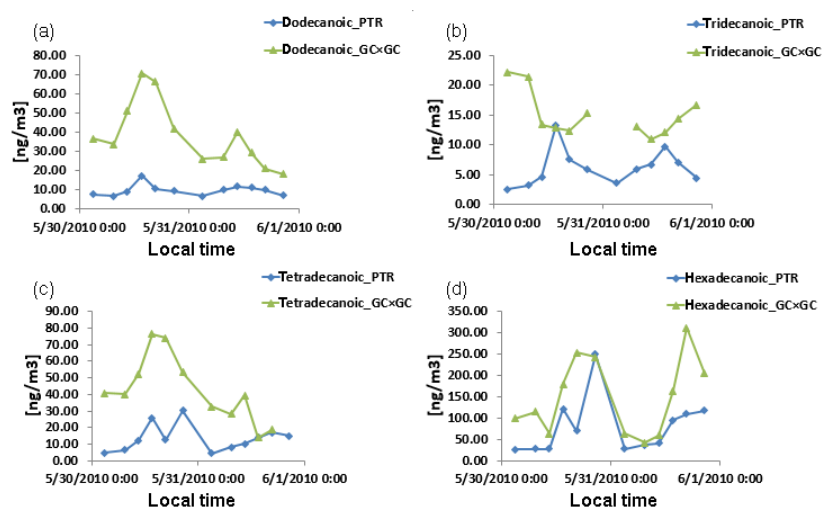

Figure 5. Time profiles for mass concentrations measured with the TD-PTR-MS and the $\mathrm{GC} \times \mathrm{GC}$ techniques for four alkanoic acids: dodecanoic (a), tridecanoic (b), tetradecanoic (c), and hexadecanoic (d).

nique, and the general comparison of the in situ TD-PTRMS and the AMS technique have been presented. Overall, a reasonable agreement is observed for temporal changes in the bulk organic aerosol (OA) between the AMS and TDPTR-MS with correlation coefficient of $0.84\left(r^{2}\right)$. A reasonable agreement is also observed between temporal changes in the 123 compounds measured from quartz filters by the GC $\times$ GC/TOF-MS and the 64 corresponding masses detected by the TD-PTR-MS for the Los Angeles area, with $r^{2}$ of 0.67 .

The calibration measurements showed that n-alkanoic acids with molecular mass $\left(M_{r}\right)$ below $290 \mathrm{amu}$ are detected at recovery fractions above $60 \%$. Monocarboxylic acids heavier than $300 \mathrm{amu}$, and monocarboxylic acids containing double bonds in the mass range $226<M_{r}<290$ am exhibit recovery fractions below 4 and $38 \%$ respectively. This is likely caused by the fact that higher temperatures are needed to desorb these compounds from the filters and that thermal decomposition of monocarboxylic acids containing double bonds starts taking place before the compounds are fully desorbed. Future measurements of other light unsaturated acids $\left(M_{r}<226 \mathrm{amu}\right)$ are needed to test whether their recovery fractions are close to unity, as it is the case for light alkanoic acids $\left(M_{r}<290 \mathrm{amu}\right)$. Based on the measured re- covery fractions of n-alkanoic acid $\left(M_{r}<290 \mathrm{amu}\right)$ measurements, a calibration factor of 1.45 has been established and applied to the in situ TD-PTR-MS measurements of alkanoic acids $\left(M_{r}<290 \mathrm{amu}\right)$.

For the comparison of the in situ TD-PTR-MS and the offline $\mathrm{GC} \times \mathrm{GC} / \mathrm{TOF}-\mathrm{MS}$ technique, 123 of 132 compounds measured by the GC $\times$ GC/TOF-MS could be matched with ions measured by the PTR-MS. The applied mass matching algorithm took the loss of a water molecule into account, while other fragmentation patterns were not considered. The comparison indicated that the techniques agree reasonably well for single compounds: for most compounds with mass concentrations above $2 \mathrm{ng} \mathrm{m}^{-3}$ the $\mathrm{PTR} /(\mathrm{GC} \times \mathrm{GC})$ ratio was between 0.25 and 2 , which is close to the expected agreement based on the stated accuracies of both instruments. Compounds detected at levels below $2 \mathrm{ng} \mathrm{m}^{-3}$ with the GC $\times$ GC/TOF-MS exhibited higher concentrations at the corresponding ions detected by the TDPTR-MS. This is likely caused by other organic compounds that were detected by the TD-PTR-MS at the corresponding $m / z$ values but were not specifically identified with the $\mathrm{GC} \times \mathrm{GC} / \mathrm{TOF}-\mathrm{MS}$ technique (only 132 compounds were identified out of the $\sim 1100$ resolved peaks).

Most classes of compounds were detected well by the TD-PTR-MS. The positive filter sampling artifacts, caused by the semivolatile nature of the do-, tri-, and tetradecanoic acids, likely resulted in the higher concentrations observed by the GC $\times$ GC/TOF-MS and lower correlations between the $\mathrm{GC} \times \mathrm{GC} / \mathrm{TOF}-\mathrm{MS}$ and TD-PTR-MS measurements.

Acknowledgements. The PTR-TOF-MS has been funded by the Netherlands Organization for Scientific Research (NWO) under the ALW-Middelgroot program (grant 834.08.002). Deployment of the PTR-TOF-MS at CalNex and the analysis using GC $\times$ GC/TOFMS at UC Berkeley were supported by the National Oceanic and Atmospheric Administration (grant NA10OAR4310104). We would like to acknowledge Patrick Hayes and Jose Jimenez for providing the AMS data. We would like to thank Gabriel Isaacman for preparing the filters with standard mixture. The authors gratefully acknowledge the NOAA Air Resources Laboratory (ARL) for the provision of the HYSPLIT transport and dispersion model and/or READY website (http://www.ready.noaa.gov) used in this publication. 
Edited by: G. Phillips

\section{References}

Boucher, O., Randall, D., Artaxo, P., Bretherton, C., Feingold, G., Forster, P., Kerminen, V.-M., Kondo, Y., Liao, H., Lohmann, U., Rasch, P., Satheesh, S. K., Sherwood, S., Stevens, B. and Zhang, X. Y.: Clouds and Aerosols, in: Climate Change 2013: The Physical Science Basis. Contribution of Working Group I to the Fifth Assessment Report of the Intergovernmental Panel on Climate Change, edited by: Stocker, T. F., Qin, D., Plattner, G.-K., Tignor, M., Allen, S. K., Boschung, J., Nauels, A., Xia, Y., Bex, V., and Midgley, P. M., Cambridge University Press, Cambridge, United Kingdom and New York, NY, USA, 571-657, 2013.

Cappa, C. D., Lovejoy, E. R., and Ravishankara, A. R.: Evaporation Rates and Vapor Pressures of the Even-Numbered C8C18 Monocarboxylic Acids, J. Phys. Chem. A, 112, 3959-3964, 2008.

Chan, A. W. H., Isaacman, G., Wilson, K. R., Worton, D. R., Ruehl, C. R., Nah, T., Gentner, D. R., Dallmann, T. E., Kirchstetter, T. W., Harley, R. A., Gilman, J. B., Kuster, W. C., de Gouw, J. A., Offenberg, J. H., Kleindienst, T. E., Lin, Y. H., Rubitschun, C. L., Surratt, J. D., Hayes, P. L., Jimenez, J. L., and Goldstein, A. H.: Detailed chemical characterization of unresolved complex mixtures in atmospheric organics: Insights into emission sources, atmospheric processing, and secondary organic aerosol formation, J. Geophys. Res.-Atmos., 118, 6783-6796, doi:10.1002/jgrd.50533, 2013.

Chandramouli, B., Jang, M., and Kamens, R. M.: Gas-particle partitioning of semi-volatile organics on organic aerosols using a predictive activity coefficient model: analysis of the effects of parameter choices on model performance, Atmos. Environ., 37, 853-864, 2003.

DeCarlo, P. F., Kimmel, J. R., Trimborn, A., Northway, M. J., Jayne, J. T., Aiken, A. C., Gonin, M., Fuhrer, K., Horvath, T., Docherty, K. S., Worsnop, D. R., and Jimenez, J. L.: Field-Deployable, High-Resolution, Time-of-Flight Aerosol Mass Spectrometer, Anal. Chem., 78, 8281-8289, 2006.

De Gouw, J. and Jimenez, J. L.: Organic aerosols in the Earth's atmosphere, Environ. Sci. Technol., 43, 7614-7618, doi:10.1021/es9006004, 2009.

Draxler, R. R. and Rolph, G.D.: HYSPLIT (Hybrid single-particle lagrangian integrated trajectory) Model access via NOAA ARL READY Website, available at: http://www.arl.noaa.gov/ HYSPLIT.php (last access: 2014), NOAA Air Resources Laboratory, College Park, MD, 2013.

Goldstein, A. H. and Galbally, I. E.: Known and unexplored organic constituents in the Earth's Atmosphere, Environ. Sci. Technol., 41, 1514-1521, 2007.

Hamilton, J., Webb, P., Lewis, A., Hopkins, J., Smith, S. and Davy, P.: Partially oxidised organic components in urban aerosol using GCXGC-TOF/MS, Atmos. Chem. Phys., 4, 1279-1290, doi:10.5194/acp-4-1279-2004, 2004.

Hayes, P. L., Ortega, A. M., Cubison, M. J., Froyd, K. D., Zhao, Y., Cliff, S. S., Hu, W. W., Toohey, D. W., Flynn, J. H., Lefer, B. L., Grossberg, N., Alvarez, S., Rappenglück, B., Taylor, W., Allan, J. D., Holloway, J. S., Gilman, J. B., Kuster, W. C., de
Gouw, J. A., Massoli, P., Zhang, X., Liu, J., Weber, R. J., Corrigan, A. L., Russell, L. M., Isaacman, G., Worton, D. R., Kreisberg, N. M., Goldstein, A. H., Thalman, R., Waxman, E. M., Volkamer, R., Lin, Y. H., Surratt, J. D., Kleindienst, T. E., Offenberg, J. H., Dusanter, S., Griffith, S., Stevens, P. S., Brioude, J., Angevine, W. M., and Jimenez, J. L.: Organic aerosol composition and sources in Pasadena, California, during the 2010 CalNex campaign, J. Geophys. Res.-Atmos., 118, 9233-9257, doi:10.1002/jgrd.50530, 2013.

Holzinger, R.: PTRwid: A new widget tool for processing PTR-TOF-MS data, Atmos. Meas. Tech., 8, 3903-3922, doi:10.5194/amt-8-3903-2015, 2015.

Holzinger, R., Williams, J., Herrmann, F., Lelieveld, J., Donahue, N. M., and Röckmann, T.: Aerosol analysis using a ThermalDesorption Proton-Transfer-Reaction Mass Spectrometer (TDPTR-MS): a new approach to study processing of organic aerosols, Atmos. Chem. Phys., 10, 2257-2267, doi:10.5194/acp10-2257-2010, 2010a.

Holzinger, R., Kasper-Giebl, A., Staudinger, M., Schauer, G., and Röckmann, T.: Analysis of the chemical composition of organic aerosol at the Mt. Sonnblick observatory using a novel high mass resolution thermal-desorption proton-transfer-reaction mass-spectrometer (hr-TD-PTR-MS), Atmos. Chem. Phys., 10, 10111-10128, doi:10.5194/acp-10-10111-2010, 2010b.

Holzinger, R., Goldstein, A. H., Hayes, P. L., Jimenez, J. L., and Timkovsky, J.: Chemical evolution of organic aerosol in Los Angeles during the CalNex 2010 study, Atmos. Chem. Phys., 13, 10125-10141, doi:10.5194/acp-13-10125-2013, 2013.

Jayne, J. T., Leard, D. C., Zhang, X. F., Davidovits, P., Smith, K. A., Kolb, C. E., and Worsnop, D. R.: Development of an aerosol mass spectrometer for size and composition analysis of submicron particles, Aerosol Sci. Tech., 33, 49-70, 2000.

Kallio, M., Jussila, M., Rissanen, T., Anttila, P., Hartonen, K., Reissell, A., Vreuls, R., Adahchour, M., and Hyötyläinen, T.: Comprehensive two-dimensional gas chromatography coupled to time-of-flight mass spectrometry in the identification of organic compounds in atmospheric aerosols from coniferous forest, J. Chromatogr. A, 1125, 234-43, doi:10.1016/j.chroma.2006.05.050, 2006.

Kanakidou, M., Seinfeld, J. H., Pandis, S. N., Barnes, I., Dentener, F. J., Facchini, M. C., Van Dingenen, R., Ervens, B., Nenes, A., Nielsen, C. J., Swietlicki, E., Putaud, J. P., Balkanski, Y., Fuzzi, S., Horth, J., Moortgat, G. K., Winterhalter, R., Myhre, C. E. L., Tsigaridis, K., Vignati, E., Stephanou, E. G., and Wilson, J.: Organic aerosol and global climate modelling: a review, Atmos. Chem. Phys., 5, 1053-1123, doi:10.5194/acp-5-1053-2005, 2005.

Kawamura, K. and Sakaguchi, F.: Molecular distributions of water soluble dicarboxylic acids in marine aerosols over the $\mathrm{Pa}-$ cific Ocean including tropics, J. Geophys. Res., 104, 3501-3509, 1999.

Legrand, M. and De Angelis, M.: Light carboxylic acids in Greenland ice?: A record of past forest fires and vegetation emissions from the boreal zone, J. Geophys. Res., 101, 4129-4145, 1996.

Pope, C. A. and Dockery, D. W.: Health Effects of Fine Particulate Air Pollution?: Lines that Connect, J. Air Waste Manage., 56, 709-742, 2006.

Rolph, G. D.: Real-time environmental applications and Display system (READY) website, available at: http://www.ready.noaa. 
gov (last access: 21 July 2014), NOAA Air Resources Laboratory, College Park, MD, 2013.

Sihabut, T., Ray, J., Northcross, A., and McDow, S. R.: Sampling artifact estimates for alkanes, hopanes, and aliphatic carboxylic acids, Atmos. Environ., 39, 6945-6956, doi:10.1016/j.atmosenv.2005.02.053, 2005.

Timkovsky, J., Dusek, U., Henzing, J. S., Kuipers, T. L., Röckmann, T., and Holzinger, R.: Offline thermal-desorption proton-transfer-reaction mass spectrometry to study composition of organic aerosol, J. Aerosol Sci., 79, 1-14, doi:10.1016/j.jaerosci.2014.08.010, 2015.

Ulbrich, I. M., Canagaratna, M. R., Zhang, Q., Worsnop, D. R., and Jimenez, J. L.: Interpretation of organic components from Positive Matrix Factorization of aerosol mass spectrometric data, Atmos. Chem. Phys., 9, 2891-2918, doi:10.5194/acp-9-2891-2009, 2009.

Veres, P. R., Roberts, J. M., Cochran, A. K., Gilman, J. B., Kuster, W. C., Holloway, J. S., Graus, M., Flynn, J., Lefer, B., Warneke, C., and de Gouw, J.: Evidence of rapid production of organic acids in an urban air mass, Geophys. Res. Lett., 38, L17807, doi:10.1029/2011GL048420, 2011.

Vogel, A. L., Äijälä, M., Brüggemann, M., Ehn, M., Junninen, H., Petäjä, T., Worsnop, D. R., Kulmala, M., Williams, J., and Hoffmann, T.: Online atmospheric pressure chemical ionization ion trap mass spectrometry (APCI-IT-MSn) for measuring organic acids in concentrated bulk aerosol - a laboratory and field study, Atmos. Meas. Tech., 6, 431-443, doi:10.5194/amt-6-431-2013, 2013.

Weber, R. J., Orsini, D., Daun, Y., Lee, Y.-N., Klotz, P. J., and Brechtel, F.: A Particle-into-Liquid Collector for Rapid Measurement of Aerosol Bulk Chemical Composition, Aerosol Sci. Tech., 35, 718-727, doi:10.1080/02786820152546761, 2001.
Williams, B. J., Goldstein, A. H., Kreisberg, N. M., and Hering, S. V.: In situ measurements of gas/particle-phase transitions for atmospheric semivolatile organic compounds, P. Natl. Acad. Sci. USA, 107, 6676-6681, doi:10.1073/pnas.0911858107, 2010.

Williams, B. J., Jayne, J. T., Lambe, A. T., Hohaus, T., Kimmel, J. R., Sueper, D., Brooks, W., Williams, L. R., Trimborn, A. M., Martinez, R. E., Hayes, P. L., Jimenez, J.L., Kreisberg, N. M., Hering, S. V., Worton, D. R., Goldstein, A. H., and Worsnop, D. R.: The First Combined Thermal Desorption Aerosol Gas Chromatograph - Aerosol Mass Spectrometer (TAG-AMS), Aerosol Sci. Tech., 48, 358-370, doi:10.1080/02786826.2013.875114, 2014.

Yatavelli, R. L. N., Stark, H., Thompson, S. L., Kimmel, J. R., Cubison, M. J., Day, D. A., Campuzano-Jost, P., Palm, B. B., Hodzic, A., Thornton, J. A., Jayne, J. T., Worsnop, D. R., and Jimenez, J. L.: Semicontinuous measurements of gas-particle partitioning of organic acids in a ponderosa pine forest using a MOVI-HRToFCIMS, Atmos. Chem. Phys., 14, 1527-1546, doi:10.5194/acp14-1527-2014, 2014.

Yu, J. Z., Xu, J., and Yang, H.: Charring characteristics of atmospheric organic particulate matter in thermal analysis, Environ. Sci. Technol., 36, 754-761, 2002.

Zhao, J. and Zhang, R. Y.: Proton transfer reaction rate constants between hydronium ion $\left(\mathrm{H}_{3} \mathrm{O}(+)\right)$ and volatile organic compounds, Atmos. Environ., 38, 2177-2185, 2004.

Zhao, Y., Kreisberg, N. M., Worton, D. R., Isaacman, G., Gentner, D. R., Chan, A. W. H., Weber, R. J., Liu, S., Day, D. A., Russell, L. M., Hering, S. V., and Goldstein, A. H.: Sources of organic aerosol investigated using organic compounds as tracers measured during CalNex in Bakersfield, J. Geophys. Res., 118, 11388-11398, doi:10.1002/jgrd.50825, 2013. 